\title{
SECTORAL CONTRIBUTIONS TO NIGERIAN GROSS DOMESTIC PRODUCT USING A VAR APPROACH
}

\section{UCHECHUKWU GEORGE AND ELIZABETH UWEMEDIMOH IBIOK}

(Received 11 September 2013; Revision Accepted 11 June 2015)

\begin{abstract}
This study analyzed sectoral contributions to Gross Domestic Product by Agriculture, Industry and services sectors of the economy using a Vector Autoregressive (VAR) approach. The test of stationarity using Augmented Dickey Fuller (ADF) showed that all the variables were integrated of order one. Granger causality was used to find the linkages among the variables under consideration. The result showed bilateral causality between GDP and sectoral contribution to GDP by Industry. Thereafter the unrestricted VAR parameter estimate was obtained for GDP and sectoral contribution to GDP by Industry. In conclusion, it is recommended that the Nigerian government should come up with strategic master plan to diversify the economy using the Agriculture and services sectors since the Nigerian economy from our analysis is grossly dependent on sectoral contributions of Industry to GDP.
\end{abstract}

KEYWORDS: Granger causality, Unit root, VAR model and sectoral contribution

\section{INTRODUCTION}

Information on the current state of economic activity is a crucial ingredient for policy making, as choice of the appropriate policy stance relies on the updated knowledge of the macroeconomic framework Roberto and Guiseppe (2004). The development of the Nigerian economy is one that emanated from a monoculture economy being based purely on the agricultural sector of the economy, therefore making the sector the main stay of the economy. The discovery of the crude oil in 1956 in commercial quantity has however nullified this assertion, since it has relegated the hitherto main stay of the economy to the background. It is however important to note that the various sectors of any economy has a contribution to the development of that economy, this is to say that no matter how small the contribution of any sector, to the national income of that economy is, it adds up to the aggregate income of the economy and thus contributing directly or indirectly to the gross domestic earnings of such economy Abdulrasheed (2010). The contribution of the various activity sectors to GDP can never be over emphasized. The value of Nigerian GDP has been on a steady increase, it becomes pertinent to study how Agriculture, Industry and Services sectors contribute to GDP based on the huge amount of budgetary allocation by the government to these key sectors of the economy in line with the transformation agenda of the present Federal government. Also, the vision of making Nigeria one of the top twenty economies of the world by the year 2020 can only be possible if the Nigerian economy is diversified. This work therefore seeks to determine how diversified the Nigerian economy is at present using
VAR approach to model sectoral contributions to GDP and the growth process of the economy.

\subsection{PREVIOUS RESEARCH}

Usman and ljaiya (2011) studied budgetary allocations and sectoral contributions to economic development in Nigeria using a Vector Autoregressive (VAR) model to estimate the impact of the sectors on GDP, they examined the underlying factors responsible for the poor performance of sectoral allocation to key sectors (Agriculture, Education, Health and Transport) of the economy. Their result showed a clear response of the GDP to budgetary allocations on Education, Health and transport except Agriculture. To increase the sectors contribution to the economy, they suggested that more budgetary allocation should be provided for the key sectors.

Marwan et (2010) estimated Real GDP growth for Lebanon using 68 quarterly observations from 1993 to 2009 for ten endogenous variables and two exogenous variables selected on the basis of their economic and statistical significance. They derived a Vector Autoregressive Model with exogenous variable (VARX), a variant of the Vector Autoregressive (VAR) model that takes into account both exogenous and endogenous variables. Their results showed robust correction between the estimated and actual quarterly GDP figures indicating the ability of the model to provide a high level of accuracy in estimating real GDP growth.

Gerhard (1993) in his work on Analysis of Austrian output growth at a sectoral level used a multisectoral approach based on a VAR of sectoral output growth. This he applied to Austrian output data with particular emphases on the long-run impact of foreign

Uchechukwu George, Department of Statistics, Michael Okpara University of Agriculture, Umudike, Abia State, Nigeria.

Elizabeth Uwemedimoh Ibiok, Department of Statistics, Michael Okpara University of Agriculture, Umudike, Abia State, Nigeria 
stocks. He compared persistence estimates based on a VAR model of sectoral output growth with those obtained from univariate ARIMA models of aggregate output.

Bouton and Erkel-Rousse (2003) studied sectoral business survey as an aid to short-term macroeconomic forecasting: the service contribution. They said that service GDP growth is inimical to growth of Agriculture GDP in both the short and long-run and manufacturing and service GDPs appear to be (weakly) exogenous in the sense that they 'Granger-cause' changes in Agricultural GDP but not vice versa. Evidence on sectoral productivity indicates that increase in manufacturing and services both impact positively on agricultural productivity in the long-run. 


\subsection{METHODOLOGY}

The data for the study work was collected from Central Bank of Nigeria statistical bulletin 2010. The data was arranged on quarterly basis and was collected for a period of thirty years (1981-2010). The data showed Nigerian GDP, contributions to GDP from Agriculture, Industry, and Services all expressed in millions of naira. The Vector Autoregressive (VAR) model was used in this study, according to Gujarati and Porter (2009) for us to model a set of variable using the VAR model; we must first find out if the economic variables are stationary individually.

The unit root test

A test of stationarity or non stationarity that has become popular over the past several years is the unit root test. This is estimated using the Augmented Dickey Fuller (ADF) test

$\Delta Y_{t}=m+d t+g Y_{t}+\sum_{i=1}^{n} \alpha_{i} \Delta Y_{t-i}+u_{t}$

Where $\Delta Y_{t}$ is the first difference of the economic variable, $Y_{t}, m$ is the intercept (drift),

$g=1-\Phi$ where $\Phi$ is the characteristic root, $\mathrm{dt}$ is deterministic trend and $u_{t}$ is the error term.

The Granger Causality Test

The essence of the causality test is to find out inter-sectoral linkages (feedback or bilateral causality) so that we can build a VAR model for the Nigerian economy. Before we perform the causality test we must first test for the optimal lag using the basic information selection criteria. Since causality test is performed on stationary series, the lag selection criteria as well is performed on stationary series which are the first difference of the variables under consideration denoted by DLGDP, DLAGRICULTUR, DLINDUSTRY and DLSERVICES. This achieved by using the following information criteria:

Akaike's information criterion (AIC).

$\operatorname{AIC}(m)=\log \operatorname{det}\left(\hat{\varepsilon}_{\mathrm{m}}\right)+\frac{2}{T} m k^{2}$

The Hanna- Quinn Criterion (HQ)

$H Q=\log \operatorname{det}\left(\hat{\varepsilon}_{\mathrm{m}}\right)+\frac{2 \log \log T}{T}$

Schwarz Criterion (SC)

$S C(m)=\log \operatorname{det}\left(\hat{\varepsilon}_{\mathrm{m}}\right)+\frac{\log T}{T} m k^{2}$

$\hat{\varepsilon}_{\mathrm{m}}=\mathrm{T}^{-1} \sum_{t=1}^{T} \hat{u}_{\mathrm{t}} \hat{u}_{\mathrm{t}}$ is the residual covariance matrix for the model, $\mathrm{m}$ is the order of the model and $\mathrm{k}$ is the number of variables in the model and $\mathrm{T}$ is the sample size.

The Granger causality test is performed using equations 5 and 6

$$
\begin{gathered}
X_{t}=\sum_{i=1}^{n} \alpha_{i} Y_{t-i}+\sum_{j=1}^{n} \beta_{j} X_{t-j}+u_{1 t} \\
Y_{t}=\sum_{i=1}^{n} \lambda_{i} Y_{t-i}+\sum_{j=1}^{n} \delta_{j} X_{t-j}+u_{2 t}
\end{gathered}
$$

Where $\mathrm{X}$ and $\mathrm{Y}$ are economic variables, $\alpha, \beta, \lambda$ and $\delta$ are coefficients of economic variables and $u_{1 t}$ and $u_{2 t}$ are the uncorrelated error terms

The VAR model is estimated using

$$
Y_{t}=V_{0}+V_{1} t+A_{1} Y_{t-1}+---+A_{p} Y_{t-p}+u_{t}-------------------------
$$

Where $V_{0}$ and $V_{1} t$ are deterministic terms. Eqn 7 can be written in compact form

$Y_{t}=\left[V_{0}, V_{1}, A_{1},---, A_{p}\right] Z_{t-1}+u_{t}$ Where $Z_{t-1}=\left(1, t, Y_{t-1}^{I},---, Y_{t-p}^{I}\right)$

The deterministic terms may be adjusted accordingly if there is just a constant in the model or no deterministic component at all. Given a sample of size $\mathrm{T}, Y_{1}, \ldots, Y_{T}$ and $p$ presample vectors $Y_{-p+1}, \ldots, Y_{0}$, the parameters can be estimated efficiently by ordinary least squares (OLS) for each equation separately. The estimator is easily seen to be

$\left[\widehat{V}_{0}, \widehat{V}_{1}, \hat{A}_{1,}---, \hat{A}_{\mathrm{p}}\right]=\left(\sum_{t=1}^{T} Y_{t} Z_{t-1}^{I}\right)\left(\sum_{t=1}^{T} Z_{t} Z_{t-1}^{I}\right)^{-I}$ 
RESULTS AND DISCUSSIONS

Table 1: ADF Test - Levels

\begin{tabular}{|c|c|c|c|c|}
\hline \multicolumn{5}{|c|}{ Null hypothesis: Variable has unit root } \\
\hline Variable: & LGDP & LAGRICULURE & LINDUSTRY & LSERVICES \\
\hline ADF test statistic & 1.220624 & 0.357791 & -0.731498 & 1.977873 \\
\hline Test critical value: $1 \%$ level & -3.488063 & -3.488063 & -3.488063 & -3.488063 \\
\hline $5 \%$ level & -2886732 & -2.886732 & -2.886732 & -2.886732 \\
\hline $10 \%$ level & -2.580281 & -2.580281 & -2.580281 & -2.580281 \\
\hline MacKinnon prob-value & 0.9982 & 0.9803 & 0.8337 & 0.9999 \\
\hline
\end{tabular}

From Table 1 the tests on the levels of the variables show that the null hypothesis of a unit root cannot be rejected for LGDP, LAGRICULTURE, LINDUSTRY, and LSERVICES at either the $1 \%, 5 \%$ or $10 \%$ levels; From the unit root test, we conclude that the four series are non stationary, so we make these four non stationary series, stationary by taking first difference as $D(L G D P)$, D(LAGRICULTURE), D(LINDUSTRY) and D(LSERVICES)

Table 2: ADF Test - First Difference

\begin{tabular}{|c|c|c|c|c|}
\hline Variable: & $\mathrm{D}($ LGDP $)$ & D(LAGRICULURE) & D(LINDUSTRY) & D(LSERVICES) \\
\hline ADF test statistic & -3.963922 & -4.386384 & -5.116884 & -5.633371 \\
\hline Test critical value: $1 \%$ level & -3.488063 & -3.488063 & -3.488063 & -3.488063 \\
\hline $5 \%$ level & -2.886732 & -2.886732 & -2.886732 & -2.886732 \\
\hline $10 \%$ leve & -2.580281 & -2.580281 & -2.580281 & -2.580281 \\
\hline MacKinnon prob-value & 0.0023 & 0.0005 & 0.0000 & 0.000 \\
\hline
\end{tabular}

As shown in Table 2, taking first differences renders each series stationary, with the absolute value of ADF statistics exceeding the critical values at the $1 \%, 5 \%$ or $10 \%$ levels. This confirms that the series are $1(1)$. The asymptotic critical values are from Mackinnon (1996) provided by the econometric software (Eviews Version 7).

Table 3: Lag selection-order criteria

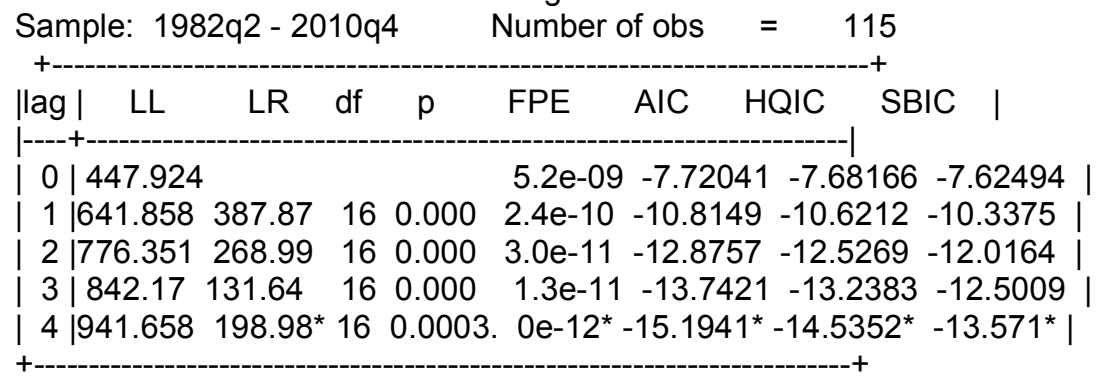

Endogenous: DLgdp DLagriculture DLindustry DLservices

According to the lag order selection criteria in Table 3 , we use lag 4 for the Granger causality test. This is because all the information criteria LR, FPE, AIC, HQIC and SBIC all selected lag 4. Note that AIC, SBIC, FPE and HQIC are Akaike information criterion, Schwartz Bayesian Information criterion, Final Prediction Error and Hannan-Quinn Information criterion. LL, df and $p$ are log likelihood, degree of freedom and probability respectively. Having identified the optimal lag of 4 , we proceed to perform the pair wise Granger Causality test for all the series DLGDP, DLAGRICULTURE, DLINDUSTRY, and DLSERVICES using Equations (5) and (6).The result of the pair wise Granger causality test is presented in Table 4. 
Table 4: Pair wise Granger Causality Tests Result

Sample: 1981Q1 2010Q4

Lags: 4

\begin{tabular}{lccc}
\hline \hline Null Hypothesis: & Obs & F-Statistic & Prob. \\
\hline \hline DLAGRICULTURE does not Granger Cause DLGDP & 115 & 0.80277 & 0.5261 \\
DLGDP does not Granger Cause DLAGRICULTURE & & 0.21092 & 0.9319 \\
\hline \hline DLINDUSTRY does not Granger Cause DLGDP & 115 & 2.87789 & 0.0262 \\
DLGDP does not Granger Cause DLINDUSTRY & & 2.76927 & 0.0310 \\
\hline \hline DLSERVICES does not Granger Cause DLGDP & \multirow{2}{*}{115} & 1.04909 & 0.3856 \\
DLGDP does not Granger Cause DLSERVICES & & 2.02585 & 0.0960 \\
\hline \hline DLINDUSTRY does not Granger Cause DLAGRICULTURE & 115 & 1.85755 & 0.1233 \\
DLAGRICULTURE does not Granger Cause DLINDUSTRY & & 3.67238 & 0.0077 \\
\hline \hline DLSERVICES does not Granger Cause DLAGRICULTURE & 115 & 1.07464 & 0.3728 \\
DLAGRICULTURE does not Granger Cause DLSERVICES & & 0.68794 & 0.6019 \\
\hline \hline DLSERVICES does not Granger Cause DLINDUSTRY & 115 & 0.30566 & 0.8736 \\
DLINDUSTRY does not Granger Cause DLSERVICES & 115 & 1.49044 & 0.2103
\end{tabular}

Pair-wise comparison of the series
DLAGRICULTURE and DLGDP

According to the results of Table 4, the P-Value (0.5261) is insignificant, so we do not reject the null hypothesis and we conclude that DLAGRICULTURE does not granger cause DLGDP. The P-value (0.9319) is also insignificant so, we do not reject the null hypothesis and we conclude that DLGDP does not Granger cause DAGRICULTURE. This means that we cannot forecast GDP using information in Agriculture sectoral contribution, thus they are independent and there is no linkage between them

\section{Pair-Wise comparison of the series DLINDUSTRY and DLGDP}

According to Table 4, the P-value $(0.0262)$ is significant so, we reject the null hypothesis and we conclude that DLINDUSTRY Granger cause DLGDP. The $P$-value $(0.0310)$ is also significant so, we reject the null hypothesis and we conclude that DLGDP Granger cause DLINDUSTRY. So DLINDUSTRY affects DLGDP and the converse is also true, it means the Granger casualty is (bidirectional) between the series, turning from DLINDUSTRY to DLGDP and the other way. This means one can successfully apply VAR model between GDP and sectoral contribution of Industry.

\section{Pair-wise Comparison of the series DLSERVICES and DLGDP}

According to Table 4 , the P-value $(0.3856)$ is insignificant so, we cannot reject the null hypothesis and we conclude that DLSERVICES does not Granger cause DLGDP. The P-value (0.0960) is insignificant so we cannot reject the null hypothesis and we conclude DLGDP does not Granger cause DLSERVICES. This mean the Granger causality is non directional between the series. This is to say that we cannot forecast GDP using information from Service sector contribution to GDP since they are independent.

\section{Pair-wise Comparison of the series DLINDUSTRY and AGRICULTURE}

According to Table 4, the P-value (0.1233) is insignificant so, we cannot reject the null hypothesis DLINDUSTRY does not Granger cause DLAGRICULTURE. But in the converse, the P-value $(0.0077)$ is significant so, we reject the null hypothesis and we conclude that DLAGRICULTURE Granger cause DLINDUSTRY This means the Granger casualty is unidirectional between the series, DLAGRICULTURE and DLINDUSTRY, running from DLAGRICULTURE to DLINDUSTRY and not the other way. This means that information on sectoral contribution to GDP by Industry in Nigeria can better be predicted using histories of sectoral contribution to GDP by Agriculture and Industry than histories of sectoral contribution to GDP by Industry alone.

\section{Pair- wise Comparison of Series, DLSERVICES and DLAGRICULTURE}

According to Table 4, the P-value $(0.3728)$ is insignificant so, we cannot reject the null hypothesis and we conclude that DLSERVICES does not Granger cause DLAGRICULTURE. The P-value (0.6019) is also insignificant so, we cannot reject the null hypothesis and we conclude that DLAGRICULTURE does not Granger cause DLSERVICES. So, DLSERVICES does not affect DLAGRICULTURE, also the converse is true, it means Granger casualty is non directional between the series. This implies that they are independent and none can be forecast in terms of the other.

\section{Pair-wise Comparison of Series DLSERVICES and DLINDUSTRY}

According to Table 4, the P-value (0.8736) is insignificant so, we cannot reject the null hypothesis and we conclude that DLSERVICES does not Granger cause DLINDUSTRY. The P-value $(0.2103)$ is also insignificant so, we cannot reject the null hypothesis that 
DLINDUSTRY does not Granger cause DLSERVICES as well, and we conclude that the Granger causality is non-directional between the series. This gain implies independence.

As stated earlier, we can only apply VAR model to variables with bilateral causality for unrestricted VAR. Having found bilateral causality between DLGDP and
DLINDUSTRY, the next step will be to estimate the parameters of the VAR Model. This is estimated using the equation 7

\section{VAR MODEL ESTIMATION RESULT}

Table 5 present the results of the unrestricted VAR.

Table 5: Vector Autoregression Estimates

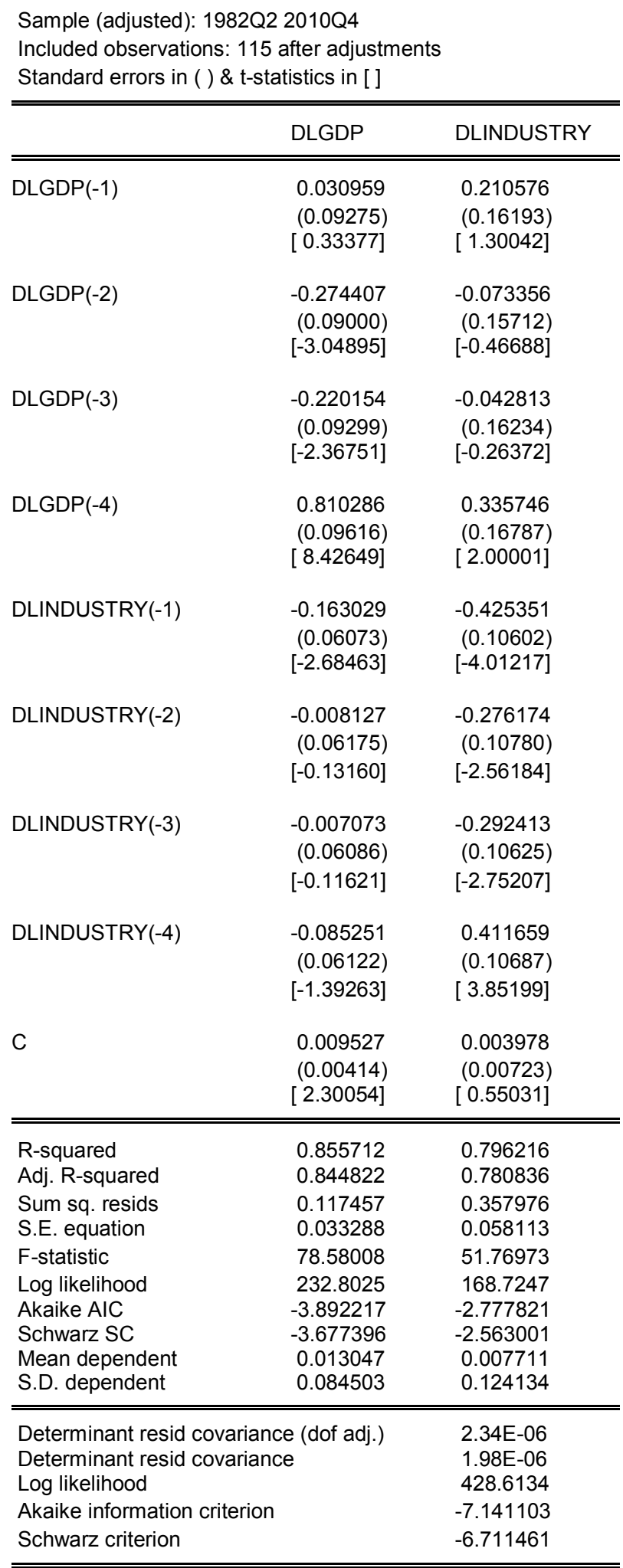


Where $Y_{t}=\left[\begin{array}{c}D L G D P_{t} \\ D L I N D U S T R Y_{t}\end{array}\right], \quad V_{0}$ is a constant term, $V_{1} t$ is deterministic term which is not included for simplicity sake. $A_{i}(i=1, \ldots, p)$ are the parameter matrix and $u_{t}$ is the error term. Table 5 present the results of the unrestricted VAR.

\subsection{CONCLUSIONS}

From the result of our analysis we identify the contribution of Industry to GDP as a major driving force in sectoral growth of Nigeria since there is bilaterally causality between sectoral contribution to GDP by Industry and GDP. This implies a linkage between the industrial sector and GDP and confirms Nigeria economy depends on sectoral contribution of Industry based on our analysis. Despite the fact that sectoral contributions of Industry is the driving force of the Nigerian economy a lot still needs to be done in this area. Efforts should be made to ensure Nigeria's refineries works up to capacity and the subsidy in the oil sector should be removed and reinvested in the other sectors of the Nigerian economy. There should be strategic master plan for the development of the Nigerian economy which successive government should vigorously pursue since policy inconsistency has been the bane of Nigerian development.

\section{ACKNOWLEDGEMENT}

The authors wish to thank Research \& Statistics Department, Central Bank of Nigeria, Owerri for the data for this study.

\section{REFERENCES}

Abdulrasheed, A., 2010. Sectoral Contribution to Gross Domestic Product in Nigeria, 1977-2005 Nigeria forum September - October, 2010.

Bouton, $F$ and Erket-Rousse, H., 2003. Sectoral Business survey as an aid to short term Macroeconomics forecasting: The services contribution, Workshop on business and Consumer surveys, European Commission Brussels, 19 - 21 November 2003.
CBN., 2010. Central Bank of Nigeria Statistical Bulletin, 21, Abuja.

Gerhard, R., 1993. An Analysis of Austrian Output Growth at a sectoral level, Forschungbericht Research memorandum No 327.

Gujarati, D. N and Porter, D. C., 2009. Basic Econometrics $5^{\text {th }}$ edition; McGraw-Hill Companies, Inc, New York, 922pages.

Haroon, H. A and Anastasios., 2012. Cointegration and Error Correction Mechanism of Agricultural and Non-Agriculture Sector in the Palestine Economy, IRJALS Research paper 1, (3): 1-13.

Marwan, M. et al., 2010. Estimating real GDP Growth for Lebanon. Blominvest Working Paper, BLOMIVEST Bank, Lebanon, 29 pages

Roberto, G and Giuseppe, R., 2004. Using monthly Indicators to Bridge Forecast Quarterly GDP for the G7 counties, International Symposium on Forecasting of International Institute of forecasters (Sydney, 4-7, July, 2004) European Journal of Social Science 49, $195-238$.

Usman, A and ljaiya, M. A., 2011. Budgetary Allocations and sectoral contribution to Economic Development in Nigeria Interdisciplinary Journal of Contemporary Research in Business 1, (10): $83-94$. 